\title{
Introducción a la historia de la imprenta en Guipúzcoa (1585-1850)
}

\author{
Ma Dolores FernándeZ de CASADEVAnTe Romaní \\ Universidad Nacional de Educación a Distancia \\ Departamento de Literatura Española y Teoría de la Literatura \\ lolafdcr@telefonica.net
}

Recibido: Diciembre 2011

Aceptado: Julio 2012

\begin{abstract}
Resumen: Este artículo revisa la historia de los impresores guipuzcoanos desde 1585 hasta 1850. Quiénes fueron los primeros impresores que se establecieron en Guipúzcoa y bajo qué condiciones, qué proceso se seguía para poder ser impresor oficial de la provincia, cómo eran sus talleres, etc. En otras provincias la imprenta nació gracias a que existía universidad y por ello una mayor demanda, en cambio en Guipúzcoa se estableció para trabajar inicialmente para la Diputación, aunque podían aceptar otros trabajos. Desde Pedro de Borgoña hasta los Baroja y Zuazua se ha ido conformando la historia de la imprenta guipuzcoana y conocer sus impresos, que forman parte del patrimonio bibliográfico guipuzcoano. Se han buscado datos sobre sus vidas y obras en archivos, se ha ampliado y corregido la información que existía hasta ahora y en algunos casos, se han aportado nuevos datos.
\end{abstract}

Palabras clave: Imprenta en Guipúzcoa; Talleres guipuzcoanos, Diputación de Guipúzcoa.

\section{Introduction to the history of printing in Guipúzcoa (1585-1850)}

\begin{abstract}
This article reviews the history of the printers Guipúzcoa from 1585 to 1850 . Who were the first printers who settled in Guipúzcoa and under what conditions, which process was followed in order to be official printer of the province, how their workshops were, etc.. In other provinces the printing was born thanks to college and therefore greater demand, while in Gipuzcoa was established to work primarily for the council, but could accept other jobs. From Peter of Burgundy even Baroja and Zuazua have shaped the history of printing and know their printed works, which are part of the bibliographic heritage of Guipúzcoa. Data were sought about their lives and works in archives, has expanded and corrected the information that existed until now and in some cases, have provided new data.
\end{abstract}

Keywords: Printing in Guipúzcoa; Guipuzcoan workshops, provincial Council of Guipúzcoa.

\section{INTRODUCCIÓN}

El presente artículo trata de la historia de los impresores guipuzcoanos desde sus inicios hasta 1850 y de cómo con su trabajo han hecho posible que tengamos 
hoy en día impresos con pie de imprenta guipuzcoanos. No son muchos si se comparan con otras provincias con más antigüedad en la instalación de la imprenta, pero gracias a ellos podemos conocer un poco mejor nuestra historia a través de esos impresos.

En primer lugar se da cuenta de cómo se ha llevado a cabo la investigación. A continuación se da un repaso a la nómina de los impresores guipuzcoanos, tratando de ofrecer al lector los datos más relevantes que sobre cada uno de ellos se encuentran disponibles. Finalmente se exponen los resultados de esta investigación, a modo de conclusiones. Se transcriben también las siglas empleadas y por último la bibliografía.

\section{METODOLOGIA DE TRABAJO}

Para elaborar este artículo primero se recopiló la información bibliográfica que existía sobre el tema. La mayor parte eran pequeños artículos, cuya base común fue el de Serapio Múgica, que se ocupó de los impresores guipuzcoanos a través de los Libros Registro de las Juntas ${ }^{1}$.

Con posterioridad a esta primera fase se visitó el Archivo General de Guipúzcoa en Tolosa (en adelante AGG), donde fueron localizados varios memoriales y solicitudes de plazas de impresor. En el Archivo Diocesano de Guipúzcoa en San Sebastián (en adelante ADG) se solicitó la partida de matrimonio del primer impresor fijo establecido en Guipúzcoa, Martín de Huarte, para confirmar su origen.

Se efectuó una visita al Archivo de Navarra (en adelante AGN) y al Archivo General de Simancas (en adelante AGS) para conseguir más información sobre una licencia de impresión de Pedro de Borgoña, pero no se ha logrado. Tampoco se han podido localizar unos memoriales que el citado impresor había dirigido a la provincia y que supuestamente debieran haberse encontrado en el AGG y una copia en la Real Academia de la Historia de Madrid (en adelante RAHM), pero no se encuentran en ninguna de las dos supuestas ubicaciones.

Ha sucedido lo mismo con el primer impreso guipuzcoano, un memorial de Martín de Huarte dirigido a la Provincia. Se supone que estaba en el AGG pero no ha podido ser localizado. En cambio, se ha descubierto en ese mismo lugar un memorial dirigido por la viuda de Huarte, Francisca de Aculodi, a la Provincia, que no había sido citado antes por ningún estudioso.

Una de las características con las que constantemente se ha encontrado esta investigadora es que en el incendio que tuvo lugar en San Sebastián a manos de los ingleses en 1813 se quemó casi toda la ciudad y se perdieron todos los

1 MÚGICA, Serapio, "La imprenta en Guipúzcoa, examinada a través de los Libros Registros de Juntas de la provincia", Revista Internacional de Estudios Vascos, 1934, 25, p. 453-476. 1934. 
archivos, fuente imprescindible a la hora de realizar cualquier trabajo que tenga parte de su elaboración en la ciudad. Por ello no ha sido posible contar con protocolos notariales, cuentas o informes de lo entrado por la aduana o cualquier otro documento que hubiera sido necesario para completar más datos sobre los primeros impresores. Se sabe que los Huarte tuvieron su taller en la parte vieja de la ciudad, "junto a San Vicente", como figura en algún pie de imprenta, pero no se conoce si era alquilado o comprado ni la maquinaria con la que contaba.

\section{LOS IMPRESORES}

\subsection{PEDRO DE BORGOÑA (1584-1586)}

Casi todos los estudios existentes coinciden en señalar que la imprenta en Guipúzcoa comenzó en 1667 con Martín de Huarte y sus sucesores. Pero con anterioridad hubo otro impresor, Pedro de Borgoña, apenas recordado por unos pocos. Estuvo muy poco tiempo en San Sebastián e imprimió un devocionario que hasta hoy nadie ha podido localizar. ${ }^{2}$ Este impresor es citado por Serapio Múgica, Isabel Ostolaza y José María de Huarte, entre otros.

Pedro de Borgoña, natural del Franco Condado, nació hacia 1538. Es posible deducir que en 1552 ya estaba en Estella; en la visita de inspección realizada a los libreros de esa localidad en 1572, Pedro declara ser vecino de Estella desde hace unos dieciocho o veinte años. En esta ciudad trabaja como librero y encuadernador. Ha prestado servicios como impresor para Adriano de Amberes y además es soldado. A propósito de la visita realizada a los libreros en 1572, es interesante conocer cómo se realizó. Para ello contamos con el relato de José García Oro y María José Portela Silva.

Con la pragmática de 1558 Felipe II pretende conseguir un férreo control para evitar la existencia de libros heterodoxos y para ello, realiza cada año visitas a los libreros. En el caso de la visita de 1572, el Consejo Real desea controlar la demanda de libros litúrgicos. Este grupo de impresos era desde el afianzamiento del arte de la imprenta el que prevalecía por su rendimiento económico. La demanda era universal, numerosa y solvente. El nuevo rezado, como se le conoció en España, ofrecía grandes oportunidades de lucro a los empresarios del libro y por ello se procuraron privilegios de exclusiva. Veamos cómo transcurrió la visita a Pedro de Borgoña en Estella. Él y sus compañeros, declaran no haber vendido

2 TELLECHEA IDÍGORAS, José Ignacio, "Documentos sobre Pedro de Borgoña", en Boletín de Estudios Históricos sobre San Sebastián, San Sebastián, Fundación Kutxa, 1975, 9, p. 301-309. 
los nuevos libros litúrgicos, pero confesaron haber encuadernado algunos ejemplares a franciscanos y agustinos de Estella. ${ }^{3}$

... fue a la casa donde Pedro de Borgoina librero, vezino y abitante en la dicha ciudad, [...] Y demás de ello le mando que declarasse si tenia en otra parte fuera de su casa mas libros de los que en ella tenia. El qual dixo que en la dicha casa no tenia ningunos libros sino heran de las ordenanças reales deste reino asta ciento y treinta y ocho libros, algunos dellos encoardenados y otros por encoardenar $[\ldots]$

Pedro tenía en Estella un hermano, Claudio, sillero y sastre. Como conocía el mundo del cuero trabajó como encuadernador a las órdenes de Adriano de Amberes, impresor en Estella hasta 1566. Adriano de Amberes no le pagó algún trabajo y Pedro le puso un pleito. Urrizola Hualde, en su artículo, al hablar sobre Pedro de Borgoña dice que Adriano de Amberes le puso un pleito al fraile Sancho de Elso y cuando en 1668 se solucionó todo, el impresor Pedro de Borgoña, que para entonces vivía ya en Pamplona, había cobrado, lo mismo que encuadernadores y personas que tienen cargo ${ }^{4}$.

Además de encuadernador, Pedro de Borgoña fue también librero y se dedicó a la compraventa de libros a particulares. Así, en 1561 adquiere por 17 ducados unos libros viejos al clérigo Pedro Navarro de Sangüesa ${ }^{5}$. En 1568 debía a Martín de Peralta, de Olite, 37 ducados por suministrarle cuero para encuadernar. ${ }^{6}$

En 1575, Pedro de Borgoña ya vivía en Pamplona, pues se había trasladado desde Estella al ser dinamitado el castillo de la ciudad en 1572 por orden de Felipe II. En una subasta de 1574 de los bienes de Pedro Labrit, obispo de Comminges, Pedro de Borgoña compró dos ejemplares, a un real cada uno, de los Diálogos del obispo de Comminges y luego los revendió, uno de ellos por dos reales y el otro por tres. ${ }^{7}$

Tomás Porralis de Saboya, impresor en Pamplona, dice lo mismo y añade que la encuadernación en pergamino blanco costaba un real y que cada ejemplar de los Diálogos tenía 40 pliegos (Goñi Gaztambide). Otro librero de Pamplona, Juan Jacques, declara por el contrario que los 600 ejemplares estaban sin encuadernar y

3 GARCÍA ORO, José, Ma José PORTELA SILVA, Felipe II y los libreros, Cisneros, Madrid, 1997, p. 89 y ss.

${ }^{4}$ URRIZOLA HUALDE, Ricardo, "Sancho de Elso y su Doctrina Cristiana en "castellano y basquence", en Fontes linguae vasconum: Studia et documenta, Pamplona, Gobierno de Navarra, 2006, 38, (101), p. 109-146.

${ }^{5}$ AGN, Protocolos, Sangüesa, notario Martín Brun, legajo 14.

${ }^{6}$ AGN, Protocolos, Olite, notario Martín Ruiz, legajo 16.

${ }^{7}$ GOÑI GAZTAMBIDE, José. "Pedro Labrit de Navarra, obispo de Comminges. Su vida y sus obras (c. 1504-1567)", Príncipe de Viana, Pamplona, Gobierno de Navarra, 1951, 190, p. 559-596. 
que la encuadernación en pergaminos costaba medio real, como cita asimismo Goñi Gaztambide.

En 1580 fallece Claudio de Borgoña, hermano de Pedro, y en su testamento declara deber 9 ducados a Pedro en concepto de fianza por unos libros entregados al librero Juan de Baquedano, vecino de Estella. ${ }^{8}$ En 1581 Pedro quiere entrar en el negocio de la venta de libros adaptados a la liturgia tridentina, pero no tiene suerte, pues el obispado pamplonés tiene casi la exclusiva. Interpone un pleito al respecto, pero lo pierde. Sabemos que aprendió a imprimir con su maestro Adriano de Amberes y aunque no se haya encontrado ningún impreso con su firma, podemos adivinar que en los firmados por Amberes está de alguna manera su huella. En 1583 había comprado todos los instrumentos y aparejos de su imprenta y estaba editando en Pamplona algunas obras con licencia del Consejo (no las hemos hallado) y según la documentación consultada, Borgoña trabajaba para otras regiones, sobre todo para Castilla y Aragón, pues mucho de lo que se imprimía en Navarra era en vascuence y el mercado era muy limitado, como es lógico suponer.

La Inquisición de Logroño, de la que dependía tanto Navarra como el País Vasco, encargó a Pedro de Borgoña la impresión de varias hojas con sus blancos y el impresor solicitó la autorización al Consejo, que se la denegó. Esto dio origen a un proceso en 1583, que a continuación se detalla: Tomás Porralis de Saboya se estableció en Pamplona entre 1570 y 1596. Sucedió a Amberes y quedó como único impresor. ${ }^{9}$ En 1578 la ciudad de Pamplona le otorgaba un salario anual de 50 ducados, con lo que de alguna manera se hacía oficial su trabajo como impresor único de la ciudad. El contrato tenía una duración de diez años y a cambio se le exigía tener la imprenta al día con todo el aparejo necesario y la exclusiva de imprimir. Borgoña entró en escena cuando Porralis ya actuaba como impresor único y oficial. Alegó su condición de soldado y reclamó la jurisdicción militar para que le ayudara en el pleito, pero el Consejo le ordenó en agosto de 1583 que no imprimiese con apercibimiento de que procedería contra él rigurosamente.

Borgoña no se desanimó y al mes siguiente presentó ciertas scripturas de escomuniones y otras para el juzgado de probisor o Vicario general de la ciudad de Logroño, y el Consejo le recordó la prohibición anterior que seguía vigente. Se defendió al decir que llevaba 20 años de servicio, que tenía todos los aparejos e instrumentos, que le habían costado más de 120 ducados, e incluso que había llegado a imprimir con el permiso de la ciudad de Pamplona. A instancias de Porralis, la ciudad de Pamplona intervino y testificó a favor de este último. Decía que:

\footnotetext{
${ }^{8}$ AGN, Procesos, leg. $\mathrm{n}^{\circ} 99375$.

${ }^{9}$ HUARTE JÁUREGUI, José María de, "La imprenta en Guipúzcoa: el primer impresor", en Euskalerriaren Alde, San Sebastián, Imprenta de Martín Mena y Cia., 1926, XVI, (265), p. 1-6.
} 
...tenía muy buena estampa y muchas y diferentes letras de molde muy buenas.

Para rematar, decía que Porralis estaba

...examinado y aprobado y le correspondía imprimir todas las obras que en este Reino se hacen y otras muchas más.

Así las cosas, Pedro de Borgoña decidió marchar a San Sebastián y probar suerte. Estuvo dos años, entre 1584 y 1586. En los libros de Registro de las Juntas hemos hallado las siguientes peticiones de Pedro de Borgoña que transcribimos ${ }^{10}$ :

\section{Registro de las Juntas Generales de 1584. Fuenterrabía, 14-24 noviembre}

Petiçión de Pedro de Borgoña, librero.

Este día se leyó otra petiçión de Pedro de Borgoña, librero, encuadernador e ynprimidor de libros, por la qual pide se le ponga algún salario para que él pueda hazer asyento en la villa de San Sebastián en su ofiçio de ynpremir pues d'ello redundará mucha utilidad y probecho a toda esta Provinçia.- La qual leyda la Junta dixo que no a lugar de ponerle ningún salario y que se le deniega. ${ }^{11}$

\section{Registro de las Juntas Generales, Vergara, 4-14 de mayo, 1585}

$\mathrm{Y}$ en seguiente se leió otra petiçión de Pedro de Borgoña, librero que reside en San Sevastián, por la qual pide que para ayuda de qu'el pueda sustentarse e pasar con su ofiçio en esta Provinçia se le manden librar alguna cosa como le libra la villa de San Sebastián, que con esto offreçe de asistir y prevaleçer con el dicho su ofiçio en esta dicha Provinçia. La Junta dixo que no avía lugar lo que se pedía. ${ }^{12}$

${ }^{10}$ DÍEZ DE SALAZAR, L., Mª Rosa AYERBE, Ed., Juntas y Diputaciones de Guipúzcoa, (1584-1586, Documentos), San Sebastián, Juntas Generales de Guipúzcoa, Diputación Foral de Guipúzcoa, 1990, p. 118-221.

${ }^{11}$ ODRIOZOLA, Antonio, "Las primeras ediciones del Quaderno de Leyes de Álava (siglos XVI y XVII)", Homenaje a D. Julio Urquijo, San Sebastián, Baroja, 1951, p. 407-445. Este autor dice que en la Real Academia de Historia de Madrid hay una copia de estos memoriales, pero no se ha conseguido localizarla, ni allí han sabido dar una explicación sobre el paradero de la copia de los memoriales.

${ }^{12}$ ODRIOZOLA, op. cit. Digo lo mismo que la nota anterior. 
Adjunta a este escrito existe un testimonio con la declaración de dos testigos, los licenciados Echayde y Sada, abogados en la audiencia real del Reino de Navarra (también en Odriozola, p. 435). Ellos testifican que tanto Pamplona como Navarra le conceden una ayuda económica a Tomás Porralis. Dice que imprimió un devocionario, pero no se ha podido hallar. En el Archivo de Simancas tampoco se ha encontrado la licencia de impresión, por lo que es probable que imprimiera dicho devocionario sin licencia.

De nuevo en Pamplona tiene más pleitos. Uno por una bala de papel que vendió a un vecino de Zaragoza y que este no le pagó y otro que le ponen a él por no haber pagado el alquiler de la casa que ocupó en San Sebastián y cuyo importe asciende a 34 ducados.

En 1586 Pedro escribe un memorial en el que confirma que ha impreso el devocionario, que lo adjunta y solicita licencia para volver a imprimirlo. Dice así:

Sacra Magestad: Pedro de Borgoña, vezino desta ciudad [Pamplona], dize quel suplicante a impreso en la villa de San Sebastián un devozionario util y probechoso para todo fiel Christiano, que con esta presenta, y agora tiene necesidad de tornarlo a imprimir para la ciudad de Çaragoza, i para ello tiene necesidad de la lizencia de Vuestra Majestad. Por ende pide i suplica a Vuestra Magestad mande cometello para que lo bean y bisto le mande dar licencia y pide justicia. Pedro de Borgoña.

Al final el tribunal concedió la licencia a Borgoña, pero sólo para imprimir el devocionario y para ello debía presentarlo antes al Consejo para su aprobación o no. Cuando parecía que la luz iba a brillar para el impresor, el relator Arrieta, en nombre de la ciudad, decomisó los pliegos a medio imprimir y acabó con la aventura impresora de Borgoña. ¿Por qué ese empeño en no autorizar a Borgoña a imprimir? Si una licencia de impresión, como norma, duraba diez años y había impreso en San Sebastián el devocionario dos años antes, ¿por qué solicitar una nueva licencia? Es lo que nos lleva a pensar que quizá imprimió el devocionario sin licencia del Consejo. A lo mejor fue un encargo privado de algún convento y lo hizo sin licencia. Por ahora no se puede añadir nada nuevo.

En el artículo de San Martín Casi se nos ofrece información sobre el hijo de Pedro, Andrés de Borgoña, y de una obra que imprimió en 1588, Lámpara encendida, libro de la perfection religiosa de Jerónimo Gracián de la Madre de $\operatorname{Dios}^{13}$. Entre otros datos hace referencia a un impresor muy joven, de 21 años, Andrés, que no era muy experto en el arte de imprimir. Es lógico pensar que detrás

13 SAN MARTIN CASI, Roberto, Antonio ODRIOZOLA, "Las primeras ediciones del Quaderno de Leyes de Álava (siglos XVI y XVII)", Homenaje a D. Julio Urquijo, San Sebastián, Baroja, 1951, p. 407-445. 
de él estuviera su padre, Pedro, y que este no quisiera figurar como impresor para evitar problemas con la ciudad de Pamplona. Pedro seguiría dedicándose a comprar y vender libros y a encuadernarlos. Posiblemente también trabajara como impresor puesto que conocía el oficio y se lo había enseñado a su hijo, pero no quisiera figurar con su nombre en las portadas de los libros que salieran de su taller. Es una suposición porque hasta ahora no existen certezas de ninguna obra suya, aunque sí de algunas partes de su vida, que quedó reflejada en los documentos citados.

\subsection{MARTÍN DE HUARTE (1667-1677)}

Hasta ahora se pensaba que este impresor había nacido en Amézqueta en Guipúzcoa, pero se solicitaron las partidas de matrimonio en el Archivo Diocesano de Guipúzcoa y en ellas figura que había nacido en Huarte Araquil, Navarra. Puede ser que antes de trasladarse a San Sebastián residiera en Amézqueta, pero no era guipuzcoano, sino navarro. Se le conoce como el primer impresor oficial con salario que hubo en Guipúzcoa. En 1667 escribe un memorial a la Provincia y solicita que le sea concedido el puesto de impresor. Al igual que su antecesor dice que es una pena que esta Provincia no tenga impresor como ya lo hay en otras provincias y que ya es hora de tener una imprenta oficial en Guipúzcoa:

...lo mucho que importaria a su grandeza el tener en su distrito un ympresor de libros como los ai en las demas Provincias y reinos y muy pocas las que no los tienen [...] tambien para las demas cossas que a V.S. se le ofrecieren dar a la estanpa en su distrito, lo qual parece no a logrado V.S. hasta agora, por no haver ympresor en ella. ${ }^{14}$

Parece ser que la Provincia, por no haber impresor, no pudo imprimir las Ordenanzas ni otros documentos. Para ello Huarte solicita un adelanto de 300 ducados de plata, para comprar la letra en la provincia de Zelanda, en Holanda, de la cual dice que es la mejor.

En las Juntas de Fuenterrabía de 1667 se tomó en cuenta el escrito de Huarte y se tuvo en consideración la necesidad de que hubiera un impresor oficial en la Provincia que pudiese imprimir lo que ésta necesitara. Se acordó darle el título de impresor a Martín de Huarte, permitiéndole

...que pueda imprimir cualesquiera papeles que por la Provincia se le dieran y que no pueda hacerlo otro ninguno en el distrito de ella sin licencia nuestra.

14 AGG, Leg. JD IM 1/12/43. 
El 16 de noviembre de 1668 envió de nuevo un memorial impreso a las Juntas, primer impreso conocido de este impresor, donde declaraba los gastos que había tenido al traer de Amsterdam letras nuevas y cajas por haber sido nombrado impresor oficial y pedía por ello un salario y una ayuda para esos gastos iniciales. Hasta el momento, no se ha podido localizar ese impreso citado por varias personas. Dicen que está en la RAHM pero a fecha de hoy, no se ha localizado ni en la Academia tienen noticia o registro de él. En su lugar hay sólo una nota manuscrita, pero no el impreso. En el AGG tampoco aparece.

Como hemos visto con anterioridad, Guipúzcoa no era una provincia rica y los Procuradores Junteros ${ }^{15}$ no estaban muy a favor de aumentar los gastos, que acrecentaban la cuota contributiva del reparto fogueral, ${ }^{16}$ pero a pesar de ello en las Juntas de Motrico de 1668 confirmaron el nombramiento de impresor. No obstante no aceptaron pagarle un salario, y además le recordaron que no podía imprimir nada relativo a la Provincia sin licencia de la misma. No era nada fácil instalarse como impresor. Así las cosas, Huarte volvió a escribir para alegar que le llegaban gentes de Navarra, Aragón y Bilbao a encargarle trabajos y necesitaba dinero para tener la imprenta al día y en pie. Su tenacidad obtuvo el premio merecido y en las Juntas de 1669 de Tolosa acordaron darle un salario de 30 ducados anuales, obligándole a Huarte a prestar fianza para conserbar y mantener la imprenta en la provincia so pena de bolber a ella todo lo que hubiere percibido de salarios. ${ }^{17}$

Huarte, también escrito Ugarte o Hugarte, trabajó para la Provincia y para particulares hasta 1677 , año en que murió.

\subsection{FRANCISCA DE ACULODI (1678-1691) Y BERNARDO DE HUARTE (1691-1696)}

Al morir Martín de Huarte las Juntas Generales de Tolosa decidieron nombrar a su viuda Francisca de Aculodi impresora de la provincia, con el mismo salario y honores que el fallecido, a condición de que mantuviera la imprenta en pie y en el estado en el que la mantenía su marido, Martín. Francisca debía cumplir estas condiciones hasta que alguno de sus hijos tuviera edad y conocimientos suficientes para hacerse cargo de ella. Francisca cobró los 30 ducados anuales hasta 1682 y 50 pesetas hasta 1692. Hacia 1689 o 90 escribe varios memoriales a la Provincia, uno

${ }^{15}$ Los Procuradores Junteros o Junteros en la actualidad, son los representantes del pueblo elegidos democráticamente que están en la Diputación. Antiguamente no se elegían democráticamente sino que había que cumplir unos requisitos: tener estudios, hablar castellano perfectamente...

${ }^{16}$ Guipúzcoa antiguamente era una hermandad de pueblos que se reunían periódicamente. Cada pueblo se repartía según sus habitantes en "fuegos", cada 5 persona un fuego, por ejemplo. A la hora de repartir gastos e ingresos, se hacía en base a los fuegos, de ahí el "reparto fogueral".

${ }^{17}$ AGG, leg. JD IM 1/12/43 
de ellos impreso y no citado por nadie con anterioridad, y suplica que le concedan a su hijo legítimo Bernardo el título de impresor. Subrayamos lo de legítimo, pues había otro hijo, Pedro, que era hijo del primer matrimonio de Martín con María de Manterola, natural de San Sebastián y también legítimo, pero hijastro de Francisca. El tratamiento no era el mismo por parte de Francisca. Bernardo era hijo del segundo matrimonio de Martín de Huarte y por ello para Francisca su único hijo era Bernardo. Dice así el memorial:

...se sirva de tener a bien la dexacion que la suplicante ha echo en Bernardo de Huarte su hixo lexitimo y del dicho su marido de la imprenta para que con mas firmeza pueda emplearse en servicio de V.S. por estar la suplicante con muchos años y no poderle servir como desea como también de onrarle con título de su impresor al dicho Bernardo con el mesmo salario en que resurxa la mejor gracia que espera de la grandeza de V.S. ${ }^{18}$

Pedro, mientras tanto, debió de separarse de su madrastra y montar su propia imprenta, según se deduce de un acuerdo de las Juntas de Segura de 1687 en las que a petición de Pedro de Huarte y Manterola, impresor y vecino de San Sebastián, y que había impreso ya algunos trabajos para la Provincia, solicita le sea concedido el título de impresor para sustituir a Francisca de Aculodi, impresora oficial, en sus ausencias o enfermedades.

Las Juntas de Azpeitia de 1688 le conceden a Pedro la futura ${ }^{19}$ de impresor de la Provincia.

Mientras tanto, la viuda, en un memorial impreso de1689-90, dice que ha tenido a su hijo Bernardo en Francia cursando estudios de latín:

... ha assistido el dicho Bernardo fuera de la Ciudad (en el Reyno de Francia) en la Arte Tipographica, exerciendo mucho tiempo, para mas perficionarse, y capacitarse en ella, a costa de su hazienda ... Haviendose aplicado assimesmo el dicho Bernardo al estudio de la lengua Latina, pues es la guia para que mas perfecta salga la Impression....

En ese mismo memorial pide que se le nombre a Bernardo impresor

...abrogando y revocando las ausencias y enfermedades y futura que se le concedió a Pedro de Huarte, hermano del dicho Bernardo.

\footnotetext{
${ }^{18}$ AGG. leg. JD IM 1/12/43

${ }^{19}$ La futura era la concesión que la Diputación daba al adjudicar el puesto de impresor oficial cuando el impresor en activo se jubilara o falleciera a quien la solicitara.
} 
Francisca de Aculodi continuó al frente del negocio con su hijo Bernardo hasta el 9 de mayo de 1691, en donde a través de escritura pública cedió sus derechos a Bernardo y le traspasó la imprenta. En esa escritura vemos una descripción de lo que era una imprenta modesta de la época, de la maquinaria y la letrería utilizada ${ }^{20}$ :

... Bernardo de Ugarte hijo lexittimo de la otorgante y del dicho Martin de Ugarte tiene por bien de hazer dejazion como la haze al susodicho de la dicha Imprenta en esta forma; de las dos prensas, el torculo, tres cajas de letras quellaman de San Agustín, tres cajas de Sisero [Cícero], tres de breviario, y tres de ala de mosca. Con todo lo demás perteneciente a la dicha Imprenta como las estampas y floretas, cabeceras y viñettas y puntas...

En ese mismo año de 1691, en las Juntas de Azcoitia, se aceptó el traspaso hecho a Bernardo y se le concedió también el salario de impresor que percibía su madre hasta entonces.

Bernardo no permaneció en San Sebastián, sino que fue un impresor itinerante. Estuvo en Pamplona y allí imprimió el $2^{\circ}$ tomo de los Anales de Navarra, del P. Moret, en 1695, aunque sin renunciar al título de impresor de Guipúzcoa. En 1696 imprimió en Tolosa el Libro de los Fueros, en casa de Miguel de Aramburu, donde montó la imprenta. Allí permaneció hasta abril de 1697 junto con su madre y su hermana Francisca. ${ }^{21}$

Más tarde, Bernardo se fue de San Sebastián, se instaló en la Corte y Guipúzcoa quedó sin impresor oficial, por lo que en las Juntas de Zarauz de 1707 se nombró como impresor a su hermano Pedro, que ya había trabajado con anterioridad para la Provincia, primero con su padre y luego por su cuenta.

\subsection{PEDRO DE HUARTE (1683-1729)}

Nació en San Sebastián el 29 de junio de 1649 y era hijo de Martín de Huarte y María de Manterola, primera esposa de Martín. En 1683 Pedro había impreso el Consulado y casa de la contratación de la noble y leal ciudad de San Sebastián; y ordenanzas con que se debe gobernar, confirmadas por el Real y Supremo Consejo de Castilla. Trabajaba por su cuenta, ya que su padre le había enseñado el oficio y no era impresor de la provincia. En ese primer impreso de 1683 figura como "Pedro de Huarte, Impresor". Es de suponer que Francisca de Aculodi

${ }^{20}$ AGG, JD IM 1/12/43
${ }^{21}$ MÚGICA ZUFIRÍA, S., op. cit., p. 453-476. 
seguía siendo la impresora oficial, si bien eso no era impedimento para que ambos trabajaran juntos y con el tiempo Pedro se independizara.

El libro de Registro de Juntas de 1703 ya lleva el pie de imprenta de Pedro impreso. Con anterioridad no era costumbre que figurara en los Libros de Registros el pie de imprenta, aunque se imprimieran desde 1680. 1703 fue el primer año que empezaron a llevar pie de imprenta. A pesar de esta falta, no es difícil deducir que los impresos corresponden a los Huarte, pues eran los únicos en la provincia que se dedicaban a este oficio. El pie de imprenta de Pedro era: "Don Pedro de Ugarte, Impresor de la Muy Noble y Muy Leal Ciudad: Año de...".

Parece ser que Pedro era impresor de la ciudad y no de la Provincia, hasta 1707, en que las Juntas de Zarauz le nombraron impresor de la Provincia. Para concederle este título, la Provincia tuvo en cuenta la habilidad y buenas condiciones de Pedro. A consecuencia de esta decisión el pie de imprenta nuevo fue el siguiente: "En San Sebastián = Por Pedro de Ugarte, impresor de las Muy Nobles y muy Leales Provincia de Guipúzcoa y esta Ciudad. Año de 1708".

Así figurará en los Libros de Registro de las Juntas. Con anterioridad, Pedro había realizado varios trabajos y vemos que en 1687 y 1688 imprime las Noticias principales y verdaderas y su pie de imprenta es: "Hállanse en casa de Pedro de Huarte" o "Hállanse en casa de Pedro de Huarte, junto a S. Vicente".

A Pedro no se le asignó ningún salario hasta que él lo reclamó en un escrito dirigido a las Juntas de Fuenterrabía de 1711. Se estudió su petición en las de Vergara de 1712 y dada su avanzada edad, la necesidad que tenía de un ayudante y lo bien que servía a la Provincia con su esmerado trabajo, se acordó que a condición de mantener la imprenta en pie, en el estado en el que estaba hasta entonces se le pagaran al año 6.800 maravedís.

Pedro fue impresor de la Provincia hasta 1729, año en el que falleció. Aparte de los Registros de las Juntas, imprimió también otras obras.

Vemos que los Huarte o Ugarte fueron los primeros impresores de Guipúzcoa. Durante 52 años mantuvieron la imprenta en pie y gracias a su esfuerzo conocemos los primeros impresos, algunos de los cuales han llegado hasta nosotros.

\subsection{MIGUEL VERA (1730-1733)}

Es un impresor poco conocido, quizás debido al poco tiempo que ejerció. No existen datos sobre su nacimiento o circunstancias vitales. Imprimió los Libros Registro de las Juntas de 1730-1733, y se tituló primero como "Impressor" y a partir de 1731 como "Impresor de la Provincia". Aparte de los Libros Registro no se ha localizado ningún otro impreso de este impresor. 


\subsection{BARTOLOMÉ RIESGO Y MONTERO (1735-1751)}

Al quedarse la provincia sin impresor hubo que buscarlo fuera. En Vitoria se contactó con Bartolomé Riesgo y Montero, que tenía establecida en aquella ciudad su imprenta. Era madrileño, hijo de Simón de Riesgo, asturiano de Monasterio de Hermo, según unos documentos y madrileño, según otros, y de Juana Montero de Espinosa, natural de Arguete (Algete), jurisdicción de Madrid $^{22}$. Bartolomé se casó con Manuela de Esquerra, originaria de Navarra y tuvieron once hijos, de los cuales sólo vivieron dos: Lorenzo, que continuó al frente del negocio familiar y Josefa Justina de la Concepción, religiosa de las Concepciones de Vergara.

Bartolomé se casó el 15 de enero de 1721 en Logroño, en la iglesia de Santa. María del Palacio con Manuela Ezquerra o Ezquerro y Sáenz de Chávarri, viuda reciente del impresor Diego Revilla Mendoza, quien trabajó como impresor en Logroño durante trece años y Bartolomé aprendió de él el oficio.

Manuela era natural de Los Arcos en Navarra, hija de Teresa Sáenz de Chávarri y de Juan José Ezquerro, ambos de la misma villa de Los Arcos, pero residentes desde hacía tiempo en Pamplona. Su padre fue impresor en Pamplona desde 1704 hasta 1729. Los hermanos de Manuela, Pedro José y Pedro Miguel, también se dedicaron al oficio de la imprenta y así se continuó la tradición familiar.

Manuela aportó al matrimonio con Bartolomé dos hijas de su anterior matrimonio con Revilla, María Fermina y Manuela. En noviembre de 1721 tuvo otra hija, fruto de su matrimonio con Bartolomé, María Javiera Riesgo Ezquerro, bautizada en la misma iglesia donde se habían casado sus padres.

De Logroño, la familia Riesgo Ezquerro pasa Vitoria en 1722 y allí heredará la imprenta su hija Manuela de Revilla cuando su padre decide ir a San Sebastián a establecerse allí, cosa que ocurrió en 1735.

Manuela se casó con Tomás de Robles y murió en Vitoria en 1778. En Vitoria, nacieron también otros tres hijos: Josefa Cristina (1723), Lorenzo José (1725) y María Josefa Dorotea (1727).

Bartolomé se trasladó a San Sebastián en 1735 y figuró como impresor de las Juntas de San Sebastián, gracias a una gestión expresa de la Provincia de Guipúzcoa, que se encomendó a José de Lopeola, tercer Director de la Real Compañía Guipuzcoana de Caracas desde su fundación, quien da cuenta de su gestión en las Juntas de Hernani de 1736, en las que manifiesta:

... que convino con aquel en que viniera a esta ciudad, ofreciéndole al efecto el salario de 50 ducados al año, más 50 escudos por una vez para gastos de viaje de su familia y conducción

${ }^{22}$ GRASES, Pedro, Escritos selectos, Col. Biblioteca Ayacucho, Caracas (Venezuela), Anauco Ed., 1989, p. 214. 
de muebles, a los que añadió la ciudad de San Sebastián 25 ducados de salario al año y otros 25 su Consulado y varios partidos muy convenientes la Real Compañía Guipuzcoana de Caracas. ${ }^{23}$

Es muy posible que influyera en esta decisión de trasladarse a la capital guipuzcoana la existencia de la Real Compañía Guipuzcoana de Caracas, con la que Riesgo mantuvo una estrecha relación.

Bartolomé Riesgo vivió a caballo por lo menos durante dos años entre Vitoria y San Sebastián, pues hay impresos firmados por él en ambas ciudades. Fue llamado a Vitoria por Don José Joaquín del Corral y Zarauz, alcalde de la ciudad, quien por encargo del Consejo de Su Magestad en el Consejo Real de Castilla, procedía contra él. Bartolomé estuvo preso por haber impreso sin licencia un almanaque, al parecer, de Don Diego Torres.

En su primer pie de imprenta, el del Registro de 1735, figura: "Impresso con permiso superior: Por Bartolomé Riesgo y Montero". Es posible que por hallarse todavía encausado necesitara un permiso de la superioridad para trabajar.

En el Registro de las Juntas de Azpeitia de 1743 el pie de imprenta que figura es el siguiente: "Impresso en San Sebastián: Por Bartolomé Riesgo y Montero, impressor de dicha M.N. y M.L. Provincia, ciudad de San Sebastián, su Consulado y de la Real Compañia de Caracas". Este pie de imprenta figuró hasta 1751, último año en el que aparece. Se tiraban 72 ejemplares del Libro Registro y cada uno costaba poco más de dos ducados.

En 1745 Bartolomé se dirige a las Juntas de Villafranca para exponer que:

...en razón de su avanzada edad y la fatiga que le producían las tareas ordinarias de su oficio, le era necesaria la ayuda de otra persona y teniendo a su hijo (Lorenzo) habilitado en aquellos menesteres, les suplica le honrasen con las ausencias, enfermedades y futura del empleo de impresor de la Provincia para que desde luego pudiera dedicarse a su servicio.

La Junta aceptó su petición. En las Juntas de Zumaya de 1747 se dirigió otra vez a la Provincia para expresar una queja, pues decía que se intentaba establecer una nueva imprenta y tienda de libros por un sujeto que no se hallaba examinado en ninguno de los dos artes y ello podía ocasionar muchos inconvenientes. La Junta remitió el asunto a los Alcaldes de San Sebastián instándoles a que no se admitiera a ningún impresor que no estuviera examinado o no tuviera título para ejercer.

No sabemos las causas exactas, pero al retirarse de la imprenta se fue a Venezuela. Quizás debido a su relación con la Real Compañía Guipuzcoana de

${ }^{23}$ MÚGICA, Serapio, op. cit. 
Caracas, se trasladó a esta ciudad, donde vivió desde 1756 hasta 1770. En 1756 figura como "abonador" ${ }^{24}$ de Juana Orea, quien había comprado una casa al doctor Blas de Orea. ${ }^{25}$

En 1761 Bartolomé otorga un poder a don Isidro Caballero y al año siguiente otorga otro a don Baltasar Solano y don Carlos. En 1764 compra un esclavo a Francisco García Gallardo y en 1766 lo vende. El 15 de marzo de 1768, se declara residente en Caracas y vecino de San Sebastián, capital de la Provincia de Guipúzcoa y da poder cumplido al señor Alcalde ordinario de primera elección y, en su defecto, al de segunda, porque ha fallecido su mujer Manuela Ezquerra en San Sebastián sin hacer testamento. El poder otorgado es para pedir inventarios de bienes, tasaciones, etc. Bartolomé quiere que todos lo bienes vayan a su legitimo hijo y para ello nombra peritos que se encarguen de todo:

...para que el ejercicio de la imprenta no pare de tener su curso, ni por ello se perjudique el ejercicio y uso de la venta de la tienda de librería, cuyo deposito y ejercicio de todo ha de quedar precisamente en el expresado don Lorenzo, mi hijo, llevando razón de todo ello, interin doy las providencias... arreglándose para ello a las ordenes que les consignare por mis cartas misivas.

El 24 de marzo firma la valoración de los libros dejados por don José de Iturriaga, según el nombramiento hecho por los albaceas del difunto don Antonio Egaña y don Francisco Guasch. Esta tasación la hace en su condición de "impresor de libros", según consta en el documento.

El 30 de marzo de 1770 Bartolomé redacta su testamento en Caracas y hace constar que sus bienes son dos oficios de imprenta, uno en Álava (el que dejó a su hija y a su yerno), y otro en San Sebastián (el que dirige su hijo Lorenzo José). Deja además una casa en San Sebastián y otra con sus tierras en Algete. Enumera otros bienes, como algunas joyas y objetos de oro y plata y 400 pesos, de los cuales voy sacando para mi manutención. Dice que tiene embarcados en el navío de don Miguel Casañas 30 fanegas de cacao que le pertenecen. Expresa que ha tenido varias intervenciones y negocios tanto en tribunales, como fuera de ellos, todo lo cual consta en sus libros de apuntes y otros papeles que tiene en su poder, así como sus créditos y deudas.

Nombra albaceas suyos al bachiller don Marcos Reyes y al doctor Jacobo Montero, abogado de la Real Audiencia. A su hijo Lorenzo José le nombra heredero universal de todos sus bienes.

\footnotetext{
${ }^{24}$ Especie de administrador.

${ }^{25}$ GRASES, Pedro, 1989, op. cit.
} 


\subsection{LORENZO JOSÉ RIESGO MONTERO (1752-1802)}

Hijo de Bartolomé, Lorenzo obtuvo la futura de su padre en 1745 como hemos visto antes. A partir de 1752 los Libros registro de las Juntas llevarán su pie de imprenta, como ocurrió a partir de la Juntas de Mondragón de 1752. El pie dice así: "Por Lorenzo Joseph Riesgo y Montero, Impresor de dicha / M. N. y M. L. Provincia, ciudad de San Sebastián / su Consulado y de la Real Compañia / Guipuzcoana de Caracas".

El mismo pie de imprenta aparecerá en el Suplemento de los Fueros, Privilegios y Ordenanzas de esta M. N. y M. L. Provincia de Guipúzcoa, de 1758.

Siguió con este pie de imprenta hasta las Juntas de Fuenterrabía de 1766, donde figura: "En San Sebastián / En la oficina de Don Lorenzo Joseph Riesgo Montero de Espinosa, Impresor de dicha M. N. y M. L. Provincia y Ciudad de San Sebastián, su muy ilustre casa de contratación y Consulado y de la Real Compañía guipuzcoana de Caracas".

En 1771, en las Juntas de San Sebastián, Lorenzo pide para su hijo Francisco Javier la futura, ausencias y enfermedad, pues hace ya nueve años que trabaja con él y conoce el oficio. Las Juntas le conceden su petición. Lorenzo añade en 1780 , en las Juntas de Zarauz, a sus títulos, el de "la Universidad Mayor de Sancti Spiritus de la villa de Oñate" y en las de Vergara de 1785 el del "Corregimiento y de la Real Compañía de Filipinas”. La compañía de Caracas desapareció en 1785, al fusionarse con la de Filipinas.

Lorenzo trabajó como impresor de la provincia hasta 1802. Hay que indicar que los Libros Registro de las Juntas particulares de Mondragón de 1794 y de Salinas de enero de 1795 se tiraron en Vitoria en la imprenta de Baltasar Manteli, impresor de la Real Sociedad Bascongada de Amigos del País. Con anterioridad, Lorenzo había sido el impresor de esta sociedad.

\subsection{FRANCISCO JAVIER RIESGO}

Se desconoce la razón, pero Francisco Javier Riesgo Montero, hijo de Lorenzo, no permaneció en San Sebastián y por lo tanto no se acogió a la futura que le habían concedido las Juntas de San Sebastián en 1771. Debió de ser un impresor itinerante, pues hemos localizado impresos suyos en Palencia en 1783, en Madrid en 1786, y en Santander en 1797. Algunos de esos impresos son:

-Disertacion medica-chirurgica: en la que se propone el mas seguro methodo de curar la Tisis Pulmonar por las Fumigaciones ó sahumerios: sacada de el quinto tomo de las memorias de la Academia Real de Cirugia de Paris, de Juan Josef de Arostegui, Palencia, Imprenta de Don Francisco Xavier Riesgo Montero, 1783. 
-El vario-logio y Coleccion de diferentes y mui [sic] diversos asuntos, que en prosa y verso escrivia don Manuel Pérez Valderrabano: primera parte, Madrid, Imprenta de Francisco Xavier Riesgo, 1786;

- Defensa de la dedicatoria de San Benito, de Tomas Calzada y Calbo, Palencia, Francisco Xavier Riesgo, 1787.

-Oracion panegirico-moral, que en la solemne fiesta de San Carlos Borromeo, en su dia 4 de noviembre de 1797..., de Antonio Miguel Yurami, Santander, Francisco Xavier Riesgo, 1797.

\subsection{ANTONIO UNDIANO (1801-1810)}

Antonio Undiano trabajaba con Lorenzo Riesgo y parecía lógico que al trasladarse Francisco Javier Riesgo a otra ciudad y retirarse Lorenzo, Antonio Undiano siguiera con el negocio y fuera nombrado impresor de la Provincia. Así figura en las Juntas de Vergara de 1803, donde se reconocen los méritos de Antonio Undiano para que se tuvieran en cuenta cuando quedara vacante la plaza de impresor. Pero no se produjo de esa manera la sucesión, porque al retirarse Lorenzo sin dejar sucesor la Provincia nombraría a De la Lama. Aunque nos consta que Antonio Undiano siguió con la imprenta de Lorenzo sin ser impresor oficial de la Provincia. Entre los años 1801 y 1810 hemos encontrado impresos que llevan su pie de imprenta. Algunos de ellos son: Doctrina Christiana, del padre Gaspar Astete, traducido al euskera por Juan de Irazusta, San Sebastián, Antonio Undiano, 1801; Ipui onac, ceintzuetan arquituco dituzten euscaldun necazari, ta gazte guciac eracaste ederrac beren vicitza zucentzeco, de Vicenta Moguel, San Sebastián, 1804. José de Undiano, seguramente hijo suyo, tuvo imprenta en Vergara, pues en 1845 y 1850 hay un par de impresos que llevan su pie de imprenta.

\subsection{FRANCISCO DE LA LAMA (1780-1828) Y SUCESORES}

Al retirarse Lorenzo se nombró impresor de la Provincia el 15 de septiembre de 1802 a Francisco de la Lama de Tolosa. Su nombramiento fue confirmado en la Junta VIII de Vergara en julio de 1803. El Corregidor le confirmó su nombramiento de impresor del Tribunal del Corregimiento el 28 de septiembre del mismo año.

La imprenta De la Lama fue la primera que tuvo la representación de la Provincia fuera de San Sebastián. Es posible que tal decisión estuviera en el hecho de que la Juntas generales celebradas en Villafranca en 1799 consideraron conveniente que el Corregimiento y la Diputación de la Provincia se fijasen en un pueblo y Tolosa fue la elegida. El acuerdo fue aprobado por el Rey, quien libró una Real Cédula en Aranjuez el 25 de mayo de 1800. En su cumplimiento se 
establecieron en esta dicha villa las dos expresadas autoridades provinciales con todas sus dependencias, entre ellas la imprenta, pero a instancia de algunos otros pueblos, que se creían perjudicados con esta medida, se restableció el sistema de tandas ${ }^{26}$ por una real provisión; y el Corregidor y Diputación se trasladaron en 1802 a la villa de Azpeitia. En Guipúzcoa el Corregidor y su Tribunal residían de manera alternativa en San Sebastián, Tolosa, Azpeitia y Azcoitia.

Francisco de la Lama ya era impresor antes de ser nombrado impresor de la Provincia. Era de Cegama y de ascendencia vizcaína. Antes de 1782 ya tenía de la Lama su taller en Tolosa, pues de esa fecha es un libro del padre Agustín Cardaveraz, Mezaco sacrificio, segunda edición y de 1780 es la Regla instituida por revelacion divina por el gran padre San Francisco de Asis.

En 1802 Francisco de la Lama se dirigió al Corregidor para solicitar el puesto de impresor, pues la Provincia ya le había nombrado su impresor el 15 de ese mismo mes y año. El documento dice así:

Señor Correjidor de la m. N. y m. L. Prova de Guipúzcoa.

Francisco de la Lama Impresor y Librero residente en la Villa de Tolosa con el más profundo respeto y veneración expone a VS:Que en falta de Dn. Lorenzo Riesgo, tenga la bondad de nombrarle para el exercicio de su profesión $[\ldots]$

Proveido. Se nombra a Franco. de la Lama por Impresor de este Tribunal. ${ }^{27}$

El pie de imprenta que utilizó de la Lama era: "En Tolosa: en la imprenta de Don Francisco de la Lama, Impresor de la expresada Provincia y del corregimiento." Así figura en el Libro Registro de las Juntas de Vergara de 1803. Las siguientes juntas hasta el año 1808 se imprimieron con el mismo pie de imprenta. Durante la guerra de la Independencia, entre los años 1809 y 1812, no se celebraron Juntas en Guipúzcoa, por lo que tampoco hay Registros de esos años. El registro de las Juntas de de Deva de julio de 1813 se imprimió en casa de Ramón Baroja, en Oyarzun y de la Lama reclamó, pues en principio solo él podía imprimir los Libros Registro. Tras atender la reclamación de De la Lama, el general Mendizábal, el 24 de febrero de 1813, le confirmó como impresor oficial y la Diputación dio por bueno el nombramiento el 12 de julio del mismo año.

${ }^{26}$ El sistema de tandas es que la Diputación o la Provincia no tenía una sede fija y se reunían en 13 pueblos por tandas. Había un orden y se seguía. Por eso los libros Registro tienen un pie de imprenta diferente cada año, cambia la ciudad.

27 TELLECHEA IDÍGORAS, José Ignacio, "Correspondencia entre D. Isaac López Mendizábal y D. Serapio Múgica (1906-1934), Noticias sobre las imprentas tolosanas de la Lama, Eusebio López y López Mendizábal", Iker, Euskaltzaindia, 1983, 2, p. 867-896. 
Se imprimieron también los Libros Registro de las Juntas de Rentería y Guetaria de1814 y 1815, además de obras religiosas del P. Cardaberaz o el Manual de Medicina práctica de Pierre Hubert Nysten. La casa Baroja imprime de nuevo los Libros Registro de las Juntas de Cestona de 1816, Segura de 1817 y las particulares de Azpeitia de Abril de 1818 y las generales de San Sebastián del mismo año, las tres primeras en Oyarzun y el último en San Sebastián, en donde fijó su imprenta de manera fija como luego se describirá.

Durante los años de 1820-22 no se celebraron Juntas y el Registro de las de 1823, de Villafranca, se imprimió de nuevo en la imprenta de Francisco de la Lama.

Hay una hecho no muy conocido y es que Francisco de la Lama estuvo prohibido por la Inquisición no una, sino dos veces. La primera fue en 1783 y se produjo por imprimir el Catón cristiano y catecismo de la doctrina cristiana y de la Lama fue sometido a un proceso de fe por esa impresión, por contener expresiones inconvenientes. ${ }^{28}$ En el Índice de 1790 aparece en la página 46 y en el de 1844 figura como año de edición de la obra 1784 y aparece en la página 68. Dice que "se la atribuye falsamente a don Joaquín Moles, presbitero. Edicto de 1785".

La siguiente fue en 1790. Según cuenta su sucesor Isaac López Mendizábal, en un escrito que le envió José Luis de la Lombana había encontrado este último un documento en el AHN. ${ }^{29}$ Por lo visto Francisco de la Lama intervino en la impresión del infolio "Carta apologética al señor Masson. Ahora sí que están buenos los huevos", que según Julián de Apraiz escribió Félix María de Samaniego contra Tomás de Iriarte. Además Lombana remite a López de Mendizábal una copia del documento del Archivo Histórico Nacional.

Francisco tenía un hijo, Juan Manuel, que tenía taller propio, como lo demuestra el hecho de que imprimiera ya en 1820 además de obras religiosas, como la Doctrina cristiana del P. Astete, el Registro de las Juntas de 1823. Su pie de imprenta era: "En Tolosa en casa de Juan Manuel de la Lama, Impresor futuro de la expresada Provincia". Se le había concedido la futura, pero a partir de 1830 ya no hay impresos con su pie de imprenta. Juan Manuel murió el 20 de diciembre de $1828 .{ }^{30}$

Los Registros de las Juntas de Azcoitia de 1824 y de Zumaya de 1825 se imprimieron en casa de Francisco. En cambio el de las Juntas particulares de San

${ }^{28}$ AHN, INQUISICIÓN, 3729, EXP.104. Dice el Documento: “Con esta y en quarenta y seis foxas utiles remitimos al relator a V. A. el expediente formado contra Dn. Francisco Lama, Impresor, y vecino de la villa de Tolosa, y otros, por haver intervenido en la Impresión del Papel, intitulado Carta Apologética al Señor Masson. Ahora si que están los huevos buenos. Con nuestro parecer al fin; para que V. A. \& Inqqn de Logroño y Agost de 1790.Dr. Dn. Antonio Joaquin Entero Ramos. Liz. Dn. Pedro Miguel y Ortega".

29 LÓPEZ MENDIZÁBAL, Isaac, "El editor de Tolosa Francisco de la Lama y la Inquisición", Boletín de la Real Sociedad Vascongada de Amigos del País (BRSVAP), San Sebastián, Mena, 1952, Año 8, (3-4), p. 521-525. AGG, Sign. 2971/001-01

${ }^{30}$ AGG, Sig. 2971/001-01. 
Sebastián de Septiembre de 1825 se tiró en San Sebastián, en casa de Ignacio Ramón Baroja igual que las generales de 1826 y 1827.

El 28 de agosto de 1828 murió Francisco de la Lama y su hijo Juan Manuel utilizó sus títulos, como consta en el pie de imprenta del Registro de las Juntas de Motrico de 1828: "En Tolosa en la imprenta de Juan Manuel de la Lama impresor de la expresada Provincia y del Tribunal del Corregimiento".

Al haber muerto el padre y el hijo, la Provincia se quedó sin impresor y solicitaron la plaza José Miguel de la Lama, hijo de Juan Manuel, Ignacio Ramón Baroja y Juan Ignacio de Mendizábal. José Miguel de la Lama, en un memorial dirigido a la Provincia el 3 de julio de 1829, dice que tiene veinte años, muchos hermanos y él es el único que puede trabajar en la imprenta, pues

...ha dedicado todos los momentos de su juventud a adiestrarse e instruirse en el interesante arte de la imprenta y hace catorce años que V.S. en la sesión octava de sus Juntas generales celebradas en la villa de Guetaria, accedió a una solicitud suya [de Francisco] concediéndole la futura de impresor de Guipúzcoa. ${ }^{31}$

Ignacio Ramón Baroja ya era impresor en San Sebastián y como hemos visto había recibido algunos encargos de la Diputación, pero no era el impresor oficial, por lo que en otro memorial del 7 de julio de 1829, solicita la plaza. Dice Baroja:

El exponente ha sabido antes de ahora ocuparse gustoso en obsequio de V.S. cuando la permanencia de la Diputación en esta ciudad, en momentos bien apurados e interesantes, así para el Real servicio, como de un inmediato y directo bien de la Provincia, ha correspondido al parecer con bastante exactitud a los encargos de la Diputación.... Todo al parecer concurre, a que el exponente pueda fundar alguna esperanza de que sea atendido en su solicitud reducida a que V.S. quería hacer en él nombramiento en propiedad de impresor de la Provincia de Guipúzcoa.

El tercero en la pugna por la plaza de impresor era Juan Ignacio Mendizábal, yerno de Francisco de la Lama, quien el 29 de junio de 1829 se dirige al Corregidor para solicitar que le nombren impresor del Corregimiento. Las razones que da son que se

...mantiene dedicado al arte de imprenta y que tiene el honor de haber servido a su Autoridad con el más puntual cumplimiento de cuanto se ha dignado ordenarle imprimir desde fines de agosto último

${ }^{31}$ AGG, JD IM 1/12/123 
en que falleció el impresor titular D. Francisco de la Lama. Que desde entonces se halla vacante y el exponente se encuentra en disposición de servirle en todas sus partes... suplica a V.S. se digne nombrarle impresor del Corregimiento de su cargo.

En la misma fecha, en otro memorial se dirige a la Provincia para solicitar también la plaza de impresor de la provincia. A su favor dice haber tenido

...la gloria de haber sido oficial de cazadores del $2^{\circ}$ Batallón de la memorable Sección de Guipúzcoa que tantas victorias de armas consiguió contra las tituladas invencibles huestes del usurpador Napoleón.

Dice también, como en el caso del Corregidor, que desde el año pasado ha realizado varios trabajos para la Diputación y por ello "suplica a V.S. se sirva conferirle el empleo de su impresor con las consideraciones, emolumentos y prerrogativas anexos a él".

La Diputación no decidió nada respecto a la plaza de impresor. Los tres impresores trabajaron por su cuenta y la imprenta de la Lama, la de Juan Manuel, siguió con el nombre de su viuda, doña María Clementina de Gárate. Así se refleja en el pie de imprenta de los Registros de Tolosa de 1829, Mondragón de 1830 y San Sebastián de 1831, además de las particulares de octubre de 1830 en Tolosa y las de agosto de 1831 de Azpeitia. Su pie de imprenta era: "En la imprenta de la viuda de la Lama". Imprimió también libros de religión, como Jesusen imitacioco edo berari jarraitcen eracusten duen liburua del P. José Cruz Echeverría o la Cristau doctrina del P. Astete y el Diccionario manual bascongado y castellano, y elementos de gramática de Luis Astigarraga Ugarte (1839). Esta fecha es la última en la que aparece su pie de imprenta. De finales de julio de 1839 es una factura de gastos que la viuda de la Lama envió a la Diputación, en la que solicita le paguen:

...por las impresiones trabajadas, para la Excma. Diputación a Guerra de esta Provincia y otros efectos suministrados. ${ }^{32}$

Francisco de la Lama, además de Juan Manuel, tenía una hija, Josefa Antonia, que se casó con Juan Ignacio de Mendizábal, natural de Goyaz. Firmaron un contrato matrimonial en 1820 por el que Francisco se obligaba a enseñarle a su yerno el oficio y a emplearle después en su imprenta, la cual se la cedía a su hija a cuenta de la legítima. ${ }^{33}$

${ }^{32}$ AGG, CA 121,16.

${ }^{33}$ MÚGICA, Serapio, op. cit. 
La imprenta continuó con el nombre de Mendizábal hasta julio de 1839, en que murió Juan Ignacio y el pie de imprenta cambió por el de "Viuda de la Lama".

Poco antes, en 1835, la Diputación carlista de Vergara, ordena la incautación de la imprenta de Mendizábal. Toda la maquinaria se trasladó a Vergara. Juan Ignacio Mendizábal, oficial de la milicia urbana de Tolosa, se hallaba ausente por haberse retirado con las tropas de la guarnición de Tolosa a San Sebastián. ${ }^{34}$

Con la maquinaria de esta imprenta publicó la Diputación carlista de Guipúzcoa en Oñate, su periódico la Gaceta Oficial, cuyo primer número apareció en 1835. La maquinaria no retornó a Tolosa. Es muy interesante al respecto leer la correspondencia que mantuvieron Serapio Múgica e Isaac López Mendizábal, editadas por Tellechea Idígoras [1983]. Transcribimos parte de una carta del 18 de Agosto de 1933 de Isaac a Serapio, dándole cuenta de este suceso:

Tolosa 18 de Agosto de 1933.

Sr. D. Serapio Mújika.

Ormáiztegi.

El 16 de Junio de 1835 la Diputación a guerra de Guipúzcoa, es decir, la Diputación carlista, desde Vergara ordenó al Sr. Alcalde de Tolosa «procediese a ocupar la imprenta de D. Juan Ignacio de Mendizábal. El 17 de Junio se procedió al Inventario y a la incautación [...] En el inventario figuran, entre otras cosas, dos prensas con sus adherentes de 720 Reales Vellón.

[...]cuando se incautaron de la Imprenta se le dijo a mi abuela que al final de la guerra los carlistas le pagarían todo el importe. Desgraciadamente, terminó la primera guerra y después la segunda y no nos pagaron ni una peseta.

Esa prisa que manifestaba D. Ignacio Lardizábal, era para publicar enseguida, su periódico la Gaceta Oficial cuyo número primero salió el 27 de Octubre de 1835.

Juan Ignacio Mendizábal y Josefa Antonia de la Lama tuvieron una hija, María Juliana, que se casó con Eusebio López en 1877. Entonces se traspasó el establecimiento a nombre de la pareja el pie de imprenta de la viuda se cambió por el de: "Casa editorial de Eusebio López, Sucesor de la viuda de Mendizábal".

${ }^{34}$ TELLECHEA IDÍGORAS, J. Ignacio, 1983, op. cit. 


\subsection{IGNACIO RAMÓN BAROJA (1812-1874)}

Ignacio Ramón Baroja nació en Oyarzun el 30 de julio de 1797. Era hijo de Rafael Martínez de Baroja y de María Josefa de Arrieta. Su padre era boticario en Oyarzun y allí montó Ignacio Ramón su primera imprenta para trasladarse después a San Sebastián, pero tras el incendio que sufrió la ciudad en 1813 volvió a Oyarzun. Las únicas edificaciones que quedaron en pie tras el incendio fueron las iglesias de Santa María y San Vicente, ambas en la parte vieja de la ciudad, y unas casas pegadas al monte Urgull. Con el incendio desaparecieron las imprentas que pudiera haber en la ciudad.

Ignacio Ramón debía de tener más máquinas en Oyarzun, pues en 1813 se imprimió el Libro Registro de las Juntas de Deba, cuyo pie de imprenta dice: "En Oyarzun. En la imprenta de Ignacio Ramón Baroxa." Publicó también un periódico titulado Pliego anual de Oyarzun. En 1814 se imprimieron las Ordenanzas del Consulado de San Sebastián. "En Oyarzun. En la imprenta de Ignacio Ramón Baroja, impresor de esta Muy ilustre casa, etc.”. Año de 1814. Alternándose con la imprenta de de la Lama en Tolosa se imprimieron los libros Registro de las Juntas de esos años.

En 1818 Baroja decidió trasladarse de nuevo a San Sebastián e instalarse allí para imprimir ese año el Registro de las Juntas generales de San Sebastián de julio. Su pie de imprenta dice: "En San Sebastián; en la imprenta de Ignacio Ramón Baroja. 1818”.

En 1826 su pie de imprenta en los Registro era: "Ignacio Ramón Baroja, impresor de esta M.N. y M.L. Ciudad y su ilustre Consulado". En 1834 publicó esta imprenta el último Registro que publicó un impresor externo, pues luego la Provincia montó una imprenta propia en Tolosa.

En 1813 Ignacio Ramón tenía 15 años, por lo que se supone que aunque el pie de imprenta llevara su nombre su representante fuera su tío Juan de Arrieta. Es lo que se deduce por una deuda pagada por la Diputación en 1813 a D. Juan Arrieta, vecino de Oyarzun, de 1.000 reales por el Registro de las Juntas últimas y otros trabajos. En 1817, en las cuentas parroquiales de Fuenterrabía se pagan 88 reales a Juan de Arrieta, impresor librero, por la encuadernación en pasta de algunos libros. $^{35}$

\subsection{OTROS IMPRESORES}

Pío Baroja, hermano de Ignacio Ramón, abuelo del escritor del mismo nombre, abrió enfrente del local de su hermano en la plaza de la Constitución una librería. Suponemos que trabajó también en la imprenta de su hermano, pues hemos

${ }^{35}$ MÚGICA, Serapio, op. cit. 
localizado libros que llevan el pie de imprenta: "Imprenta y librería de Pío Baroja”. Pío ejerció como impresor desde 1844 hasta 1862.

Pío Zuazua, en San Sebastián o José Undiano, en Vergara, tuvieron imprenta en esa época, como lo demuestra el hecho de haber localizado impresos con sus pies de imprenta.

También sabemos que Pablo de Gorosábel, encargado de los trabajos de la imprenta de V.S, es decir, de la Diputación, solicitó en 1841 en un escrito a la misma, la plaza de impresor. En el escrito dice:

...se halla desempeñando el que suscribe el expresado cargo de impresor desde el $1^{\circ}$ de junio último de 1840 , sin que hasta la fecha haya obtenido de V.S. el correspondiente nombramiento.

Solicita, asimismo,

...le aumente el sueldo pues con los diez reales de vellón diarios que se le abonan en pago de su trabajo no le es posible sostener a su familia con la decencia que desea... Suplica a V.S. sumisamente tenga a bien concederle el nombramiento de impresor de V.S. Segura, $1841 .^{36}$

\section{CONCLUSIONES}

El objetivo de este artículo es realizar una historia cronológica de los impresores guipuzcoanos para su mejor conocimiento. Se ha recopilado la información existente hasta el momento, se ha contrastado corrigiendo errores y se ha ampliado con más información encontrada en archivos, consiguiendo de esta manera tener una visión más amplia de la historia de los impresores guipuzcoanos y poner de manifiesto las condiciones de vida y de trabajo de estos hombres que con su esfuerzo contribuyeron a crear nuestro patrimonio bibliográfico. Por fortuna se ha conservado bastante bien, pues existen numerosos ejemplares en muchas bibliotecas, aunque también es cierto que de algunos impresos sólo hay un único ejemplar.

Uno de los resultados de esta investigación ha sido determinar que Martín de Huarte no era guipuzcoano, sino navarro, de Huarte Araquil. Los diferentes autores de los artículos en los que se basó originalmente este estudio se limitaban a repetir que Martín de Huarte nació en Amézqueta pero no lo comprobaban. Ante la falta de datos en las partidas de bautismo de Guipúzcoa se ha procedido a la comprobación, solicitando sus partidas de matrimonio, ya que sabía que se había

${ }^{36}$ AGG, JD IM 1/12/157 
casado en San Sebastián en las dos ocasiones. En las mismas constaba que en realidad era de Huarte Araquil (Navarra).

Otra de las indagaciones que se efectuaron sobre Pedro de Borgoña no tuvo resultados. Imprimió un devocionario del que no se ha podido hallar ningún ejemplar, pero fue el primer impresor que se estableció por poco tiempo en San Sebastián. Vino de Pamplona y estuvo en San Sebastián entre 1583 y 1585. Es el propio Pedro de Borgoña quien dice en un escrito a la Provincia que escribió un devocionario. Tal vez lo imprimió sin licencia, al no haberse hallado tampoco en el Archivo General de Simancas la licencia de impresión. Pero el devocionario es seguro que existió; lo dice el propio Pedro en un escrito a la Provincia cuando pide que le den un salario como lo hace el Ayuntamiento de San Sebastián.

Se efectuó una visita al Archivo General de Navarra y al Archivo General de Simancas para conseguir una mayor información sobre Pedro de Borgoña, pero no se ha conseguido ampliar mucho. Tampoco se han podido localizar unos memoriales que el citado impresor había dirigido a la Provincia y que supuestamente deberían haberse encontrado en el Archivo General de Guipúzcoa y una copia en la Real Academia de la Historia. En ambas ubicaciones no han sabido dar una respuesta de por qué no se encuentran esos documentos. Esta también ha sido una tarea de esclarecimiento de datos, aunque desgraciadamente se ha de concluir con un resultado negativo, pues los documentos han desaparecido. En la Real Academia de la Historia solo hay una nota manuscrita donde debía estar la copia del memorial, pero la copia no está.

Ha sucedido lo mismo con el primer impreso guipuzcoano, un memorial de Martín de Huarte dirigido a la Provincia. Algún autor lo situaba en el Archivo General de Guipúzcoa y lo había visto pero no ha podido ser localizado.

En ese mismo archivo se ha localizado un memorial dirigido por la viuda de Huarte, Francisca de Aculodi, a la Provincia, que no había sido citado antes por ningún estudioso de la materia. En ese memorial, Francisca solicita el puesto de impresor para su hijo Bernardo. Explica que lo ha tenido en Francia estudiando y que conoce el oficio. Se trata de una hoja impresa con el escudo de Guipúzcoa al inicio de la hoja, impreso a dos tintas en rojo y negro.

Con estos nuevos datos se aporta más información a la historia de la imprenta guipuzcoana, que se completa con una tipobibliografía de los impresos guipuzcoanos que forma parte de la tesis doctoral titulada La imprenta en Guipúzcoa (1585-1850).

\section{REFERENCIAS BIBLIOGRÁFICAS}

ARETA ARMENTIA, Luis María, Obra literaria de la Real Sociedad Vascongada de los Amigos del País, Vitoria, Caja de Ahorros Municipal de Vitoria, 1976. 
DÍEZ DE SALAZAR, L. M.; R. AYERBE Ed., Juntas y Diputaciones de Guipúzcoa (1584-1586, Documentos), San Sebastián, Juntas Generales de Guipúzcoa, Diputación Foral de Guipúzcoa, 1990, p. 118-221.

GARCÍA ORO, José; José PORTELA SILVA. Felipe II y los libreros. Actas de las visitas a las librerías del Reino de Castilla en 1572, Madrid, Editorial Cisneros, 1997.

GOÑI GAZTAMBIDE, José. "Pedro Labrit de Navarra, obispo de Comminges. Su vida y sus obras (c. 1504-1567)", Príncipe de Viana, Pamplona, Gobierno de Navarra, 1951, 190, p. 559-596.

GRASES, Pedro, Escritos selectos, Col. Biblioteca Ayacucho, Caracas (Venezuela), Anauco Ed., 1989.

HUARTE JÁUREGUI, José María de, "La imprenta en Guipúzcoa: el primer impresor", Euskalerriaren Alde, San Sebastián, Imprenta de Martín Mena y Cia., 1926, XVI, (265), p. 1-6.

LÓPEZ MENDIZÁBAL, Isaac: "El editor de Tolosa Francisco de la Lama y la Inquisición", en Boletín de la Real Sociedad Vascongada de Amigos del País. San Sebastián: Mena, 1952, Año 8, (3-4), p. 521-525.

MOLAS RIBALTA, Pere, Manual de Historia de España. Edad Moderna (14741808), Madrid, Espasa Calpe, 1989.

MÚGICA ZUFIRÍA, Serapio, "La imprenta en Guipúzcoa, examinada a través de los Libros Registros de Juntas de la provincia", Revista Internacional de Estudios Vascos, 1934, 25, p. 453-476.

ODRIOZOLA, Antonio. "Las primeras ediciones del Quaderno de Leyes de Álava (siglos XVI y XVII), Homenaje a D. Julio Urquijo, San Sebastián, Baroja, 1951, p. 407-445.

SAN MARTIN CASI, Roberto, "Un impresor desconocido: Andrés de Borgońa: Notas bibliográficas sobre un libro publicado en Pamplona en 1588", Mito y realidad en la historia de Navarra, Pamplona, Sociedad de Estudios Históricos de Navarra (SEHN), 1988, 3, (II), p. 271-284.

TELLECHEA IDÍGORAS, José Ignacio. "Documentos sobre Pedro de Borgoña", Boletín de Estudios Históricos sobre San Sebastián, San Sebastián, Fundación Kutxa, 1975, 9, p. 301-309.

TELLECHEA IDÍGORAS, José Ignacio. "Correspondencia entre D. Isaac López Mendizábal y D. Serapio Múgica (1906-1934). Noticias sobre las imprentas tolosanas de la Lama, Eusebio López y López Mendizábal", Iker, Euskaltzaindia, 1983, 2, p .867-896.

URRIZOLA HUALDE, Ricardo, "Sancho de Elso y su Doctrina Cristiana en "castellano y basquence", Fontes linguae vasconum: Studia et documenta, Pamplona, Gobierno de Navarra, 2006, 38, (101), p. 109-146. 